\title{
Increased expression of laminin/collagen receptor (VLA-1) on epithelium of inflamed human intestine
}

\author{
T T MacDonald, M A Horton, M Y Choy, P I Richman
}

\begin{abstract}
Immunohistochemical techniques were used to investigate the epithelial expression of VLA-1 in inflammatory bowel disease in six patients with Crohn's disease, in four patients with ulcerative colitis, and in one patient with indeterminate colitis, and compared with that in the small intestine and colons of 10 normal controls. In normal small bowel VLA-1 was expressed on crypt epithelial cells and only weakly or not at all on surface epithelium. VLA-1 was again expressed weakly in normal colon, except in one case, a 1 year old child with diarrhoea but no histological abnormalities. In small and large intestine affected with Crohn's disease, ulcerative colitis, or indeterminate colitis, there was increased expression of VLA-1 on the basolateral aspects of crypt cells and de novo expression on surface epithelium. It is suggested that this is an adaptive response to prevent epithelial cell loss as a result of inflammation in the underlying lamina propria.
\end{abstract}

Cell surface adhesion molecules of various classes have been described and shown to be involved in cellular adhesion to proteins in the interstitium and in intercellular interactions. ${ }^{1-3}$ They almost certainly have an important role in the human intestine. They may be concerned with adherence of epithelial cells to the basement membrane. ${ }^{4}$ Migration of epithelial cells from the crypts of Lieberkuhn to the tips of the villi presumably may also involve such molecules in the formation and disruption of cell-cell and cell-stromal adhesive interactions.

We have previously shown that epithelial cells express VLA-1,2,3 and 6 molecules in normal human small intestine. ${ }^{4}$ The VLA cell surface heterodimers are members of the integrin superfamily and function as receptors for extra-cellular matrix proteins such as laminin, collagen, and fibronectin. ${ }^{1-356}$ The expression of VLA-1, a cell surface heterodimer originally identified on the surface of activated $T$ cells, ${ }^{7-9}$ was particularly interesting. It was weak or absent at the bases of the crypts, was expressed on the middle to upper crypt, and was then absent or only weakly present on surface epithelium. ${ }^{4}$ This distribution is suggestive of a possible role for VLA proteins in normal bowel organogenesis.

In this paper we report on the expression of VLA-1 in the intestines of patients with inflammatory bowel disease and show that there is a dramatic increase in VLA-1 expression in Crohn's disease, ulcerative colitis, and indeterminate colitis.

\section{Methods}

Colonic biopsy specimens were obtained from four children undergoing investigation for suspected inflammatory bowel disease but in whom no intestinal disease was found. Jejunal biopsy specimens were obtained from four patients (three adults and a child) suspected of having coeliac disease but who were healthy. Resected ileum from an adult with serosal adhesions was also studied.

One colonic biopsy specimen and four pieces of resected colon from children with active ulcerative colitis were studied. A single biopsy specimen from a child with indeterminate colitis and one with Crohn's disease were also obtained. Resected ileum was obtained from five children undergoing surgery for active Crohn's disease unresponsive to medical management.

\section{IMMUNOHISTOCHEMISTRY}

Tissues were snap frozen in liquid nitrogen and stored at $-70^{\circ} \mathrm{C}$. Cryostat sections $(8 \mu \mathrm{m})$ of intestine were cut and stained immunohistochemically with monoclonal anti-VLA-1 antibody ( $T$ Cell Sciences, Cambridge, Massachusetts) using the indirect alkaline phosphatase anti-alkaline phosphatase (APAAP) technique. ${ }^{10}$ Fast red was used to localise antibody binding: sections were counterstained with Mayer's haematoxylin.

Staining of epithelial cells was graded semiquantitatively on a four point scale $( \pm,+$, ++ , or +++$)$. The range of staining was from very weak cytoplasmic and basolateral membrane staining $( \pm)$ to intense cytoplasmic and membrane staining $(t++)$. For statistical analysis the grades were converted to numbers $(t=0 \cdot 5,+=1,+t=2$, and $+++=3$ ), and the groups were compared using the Kolmogorov-Smirnov 2 group test.

\section{Results}

In normal small bowel VLA-1 was expressed on crypt epithelial cells, and was expressed only weakly or was absent from surface epithelium (table). In normal colon VLA-1 was again expressed weakly, except in one patient who had moderate staining on both crypt and surface epithelium. This was a 1 year old child with diarrhoea but in whom no histological

St Bartholomew's
Hospital, London
Department of
Paediatric
Gastroenterology
T T MacDonald
M Y Choy
ICRF Haemopoesis
Research Group
M A Horton
Department of
Histopathology
P I Richman
Correspondence to:
Dr T T MacDonald,
Department of Paediatric
Gastroenterology,
St Bartholomew's Hospital,
London EC1A 7BE
Accepted for publication
12 October 1989




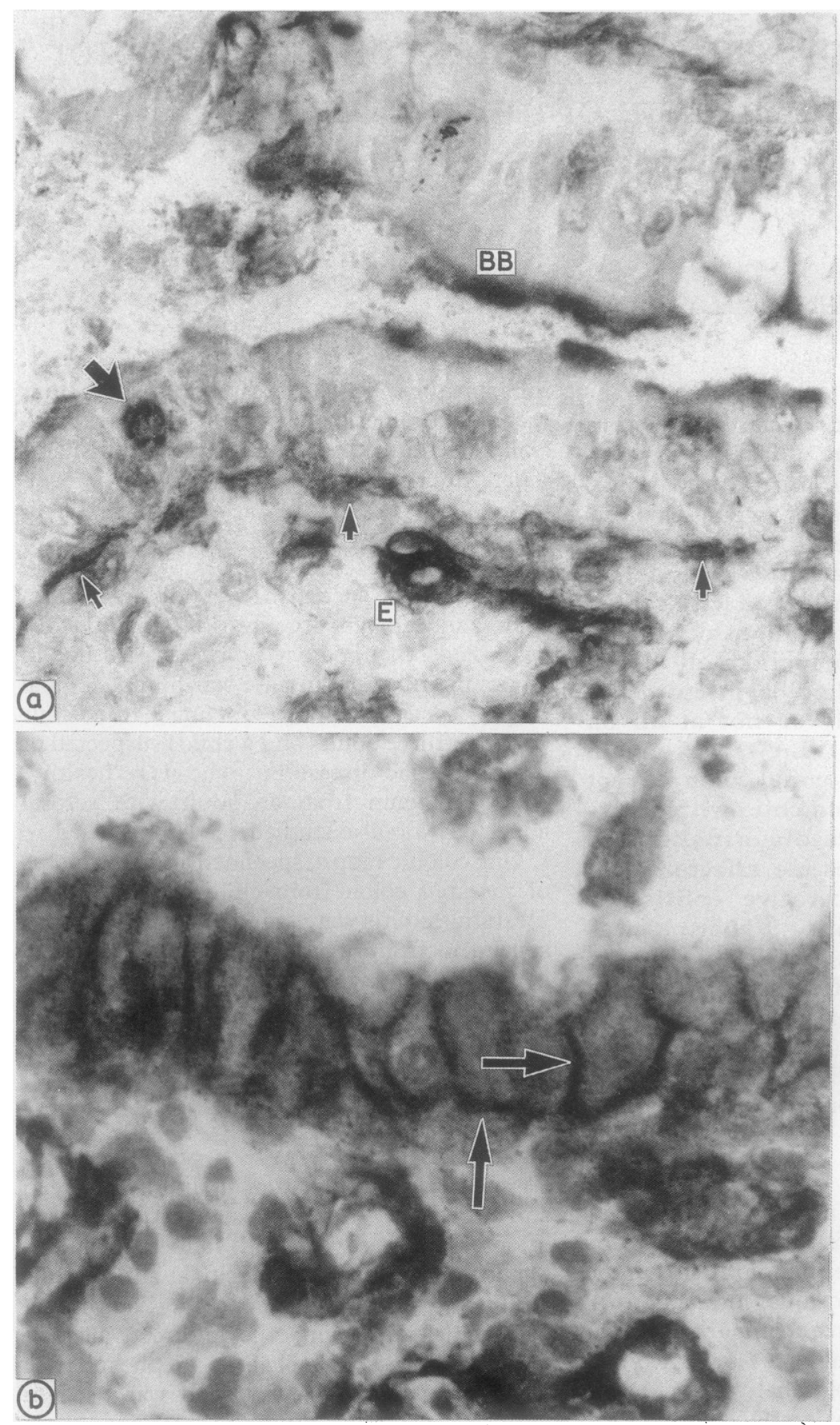

Expression of VLA-1 in normal human small intestinal epithelium (a) and in epithelium from a patient with active Crohn's disease $(b)$. In the section of normal intestine there is brush border staining (BB), aVLA-1 positive intraepithelial lymphocyte is present (large arrow), subepithelial smooth muscle cells are also VLA-1 positive (small arrows), as are endothelial cells (e) in the lamina propria. The epithelial cells themselves are negative. In Crohn's disease epithelium there is dense VLA-1 staining on the basolateral aspects of the epithelial cells (arrows). The endothelial cells of the subepithelial capillary network are also strongly VLA-1 positive.

(Immunoalkaline phosphatase.) Expression of VLA-1 on normal and diseased human
intestine

\begin{tabular}{|c|c|c|}
\hline \multirow[b]{2}{*}{ Patient } & \multicolumn{2}{|l|}{ Epithelium } \\
\hline & Crypt & Surface \\
\hline \multicolumn{3}{|l|}{ Normal small intestine: } \\
\hline 1 & + & - \\
\hline 2 & + & - \\
\hline 3 & + & + \\
\hline 4 & + & + \\
\hline 5 & & \pm \\
\hline & $p=0.006^{\star}$ & $\mathrm{p}=0.04 \dagger$ \\
\hline \multicolumn{3}{|l|}{ Crohn's small intestine: } \\
\hline 1 & +++ & ++ \\
\hline 2 & +++ & +++ \\
\hline 3 & ++ & ++ \\
\hline 4 & ++ & ++ \\
\hline 5 & +++ & + \\
\hline \multicolumn{3}{|l|}{ Normal colon: } \\
\hline 1 & ++ & ++ \\
\hline 2 & \pm & \pm \\
\hline 3 & \pm & \pm \\
\hline 4 & & \\
\hline & $p=0.023 \ddagger$ & $p=0.067 \S$ \\
\hline \multicolumn{3}{|l|}{ Ulcerative colitis colon: } \\
\hline 1 & ++ & ++ \\
\hline 2 & +++ & ++ \\
\hline 3 & +++ & +++ \\
\hline 4 & ++ & ++ \\
\hline 5 & +++ & ++ \\
\hline \multicolumn{3}{|l|}{ Crohn's disease: } \\
\hline 1 & +++ & +++ \\
\hline \multicolumn{3}{|l|}{ Indeterminate colitis: } \\
\hline 1 & +++ & $\begin{array}{l}\text { Surface epithelium } \\
\text { not identifiable in } \\
\text { section of biopsy }\end{array}$ \\
\hline
\end{tabular}

\section{Key No staining}

$\pm \quad$ Very weak cytoplasmic staining

$+\quad$ Weak cytoplasmic staining, densest basolaterally $++\quad$ Moderate cytoplasmic staining, densest basolaterally +++ Strong cytoplasmic staining, densest basolaterally *Comparison of crypts in normal small intestine with crypts in Crohn's small intestine

†Comparison of villus epithelium in normal small intestine with villus epithelium in Crohn's small intestine

†Comparison of crypt epithelium in normal colon with crypt epithelium in ulcerative colitis, Crohn's disease, and indeterminate colitis combined.

\$Comparison of surface epithelium in normal colon with surface epithelium in ulcerative colitis, Crohn's disease, and indeterminate colitis combined.

increased on accessory cells and endothelium in inflammatory sites. ${ }^{12}$ This adaptive response is mediated by inflammatory cytokines. ${ }^{12}$ Our results further emphasise the dynamic changes in molecules important in the maintenance of normal epithelial integrity which can occur following local inflammation in disease. The observation that VLA-1, an integrin receptor involved in cell adhesion to basement membranes, is upregulated in inflamed intestinal mucosa, is important for our understanding of the consequences of host responses at mucosal surfaces. Moreover, we would predict that increased VLA-1 expression on epithelium would not be confined to inflammatory bowel disease, but will be found in other conditions such as food sensitive enteropathy and parasitic infection where inflammatory cell responses into the mucosa are well recognised. This is well established in the case of HLA-DR expression in the bowel epithelium, which is increased non-specifically at any inflammatory site in the gut. ${ }^{13-15}$ The function, however, of HLA-DR on epithelium is poorly understood. In contrast, at least one of the functions of VLA-1 is known-that is, it is a cellular receptor for laminin and collagen. These two proteins are important constituents of basement membrane, ${ }^{16}$ and it is therefore not surprising that in normal bowel VLA-1 is

The idea that surface expression of cell adhesion molecules can be upregulated in inflammatory sites is not new. It is well established that the expression of ICAM-1, the ligand for the leucocyte intregrin LFA-1,11 is 
predominantly expressed on the basolateral aspect of the enterocyte where such an interaction would be expected to occur. In the specimens of inflamed intestine examined here, it was also on the basolateral aspects of the cells that VLA-1 expression was most noticeably increased (figure). Epithelial cells themselves can secrete extracellular matrix proteins, ${ }^{17}$ which may be the reason for the expression of VLA-1 on their lateral aspects. Increased expression of extracellular matrix adhesion molecules by epithelial cells during inflammation in the underlying lamina propria is probably an adaptive response to prevent extensive epithelial cell sloughing by inflammatory mediators. It will be important to analyse the regulation by inflammatory cytokines of integrin receptor expression and extracellular matrix secretion in intestinal epithelium.

Loss of epithelial integrity results in leakage of plasma proteins and fluid directly into the lumen, with severe deleterious effects on the host. It would make teleologic sense to have a mechanism in the bowel to prevent denudation of the mucosa during protective intestinal immune responses, such as parasite expulsion.

T T MacDonald is a Wellcome senior lecturer. M A Horton is supported by the Imperial Cancer Research Fund. M-Y Choy is in receipt of an award from the National Foundation for Ileitis and Colitis, New York. This work was also supported by Crohn's in Childhood Research Appeal.

1 Ruoslahti E, Pierschbacher MD. New perspectives in cell adhesion: RGD and integrins. Science 1987;238:491-7.

2 Hynes RO. Integrins: a family of cell surface receptors. Cell 1987;48:549-54.

3 Hemler ME. Adhesive protein receptors on haematopoetic cells. Immunology Today 1988;9:109-13.

4 Choy M-Y, Richman PI, Horton MA MacDonald TT. Expression of the VLA family of integrins in human intestine. J Pathol (in press).

5 Hemler ME, Huang C, Schwarz L. The VLA protein family. Characterisation of five distinct cell surface heterodimers each with a common 130,000 molecular weight $\beta$ subunit. J Biol Chem 1987;262:3300-9.

6 Kishimoto TK, O'Connor K, Lee A, Roberts TM, Springer TA. Cloning of the $\beta$ subunit of the leucocyte adhesion proteins: homology to an extracellular matrix recepto defines a novel supergene family. Cell 1987;48:681-90.

7 Hemler ME, Ware CF, Strominger JL. Characterization of a novel differentiation antigen complex recognised by a monoclonal antibody (A-1A5): unique activation specific monoclonal antibody (A-1A5): unique activation specific
molezule on stimulated $\mathrm{T}$ cells. $J$ Immunol 1983;131: molezule

8 Hemler ME, Jacobson JG. Cell matrix adhesion related proteins VLA-1 and VLA-2: regulation of expression on T cells. J Immunol 1987;138:2941-8.

9 Hemler ME, Jacobson JG, Strominger JL. Biochemical characterisation of VLA1 and VLA2 cell surface heterodimers on activated $\mathrm{T}$ cells. $J$ Biol Chem 1985;26i: $15246-52$.

10 Isaacs on PG, Wright DH. Immunocytochemistry of lymphoreticular tumours. In: Polak J, van Noorden S, eds. Immunocytochemistry. Practical applications in pathology Immunocytochemistry. Practical applications in pathology
and biology. Bristol: John Wright and Sons, 1986:249.

11 Marlin SD, Springer TA. Purified intracellular adhesion molecule-1 (ICAM-1) is a ligand for lymphocyte function molecule-1 (ICAM-1) is a ligand for lymphocyte

12 Dustin ML, Rothlein R, Bhan AK, Dinarello CA, Springer TA. Induction by IL-1, tissue distribution, biochemistry and function of a natural adherence molecule (ICAM-1) J Immunol 1986;137:245-54.

13 Selby WS, Janossy G, Mason DY, Jewell DP. Expression of HLA-DR antigens by colonic epithelium in inflammatory bowel disease. Clin Exp Immunol 1983;53:614-8.

14 Ar to A, Savilahti E, Taenio V-M, Verkasalo M, Klemola T. HLA-DR expression, natural killer cells and IgE containii:g cells in the jejunal mucosa of coeliac children. Gut ii:g cells in the
$1987 ; 28: 988-94$.

15 Spencer JM, Pugh S, Isaacson PG. HLA-D region antigen expression on stomach epithelium in absence of autoantibodies. Lancet 1986;ii:983.

16 Madri JA, Pratt BM, Yurcheno PD, Furthmayr H. The ultrastructural organisation and architecture of basement membranes. In: Basement membranes and cell movement. London: Pitman, 1984:6-24.

17 Bissel MJ, Hall HG, Parry G. How does the extracellular matrix direct gene expression. $J$ Theoret Biol 1982;99: $31-68$. 